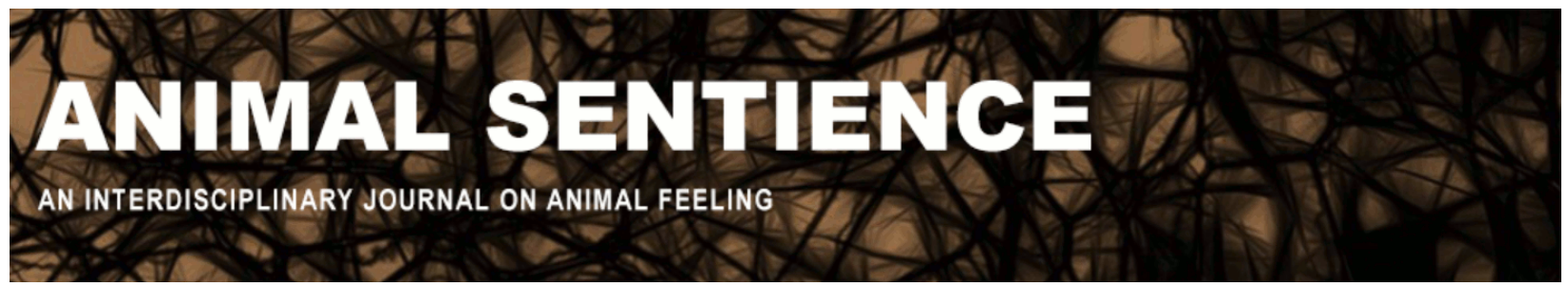

Reber, Arthur S. (2017) To identify all the relevant factors is to explain feeling. Animal Sentience 11(14)

DOI: $10.51291 / 2377-7478.1189$

Date of submission: 2017-01-22

Date of acceptance: 2017-02-02

(c)

This article has appeared in the journal Animal

Sentience, a peer-reviewed journal on animal

cognition and feeling. It has been made open access,

free for all, by WellBeing International and deposited

in the WBI Studies Repository. For more information,

please contact

wbisr-info@wellbeingintl.org.

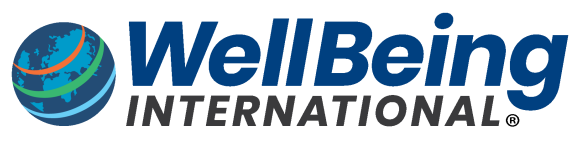

SOLUTIONS FOR PEOPLE, ANIMALS AND ENVIRONMENT 


\title{
To identify all the relevant factors is to explain feeling
}

\author{
Response II to Commentary on Reber on Origins of Mind
}

\author{
Arthur S. Reber \\ Department of Psychology, University of British Columbia
}

\begin{abstract}
Several additional comments on Reber (2016a) have appeared. Like those addressed in Reber (2016b), they reflect points of agreement and disagreement on various elements of my Cellular Basis of Consciousness (CBC) model. Some, however, seem to have missed key points. I'm willing to take some responsibility for this. Perhaps I was not clear about some of the more radical points of the model. Hopefully the case-by-case review here will help.
\end{abstract}

\begin{abstract}
Arthur S. Reber is Broeklundian Professor of Psychology, Emeritus, Brooklyn College and Graduate Center of the City University of New York, and currently Visiting Professor, Psychology, University of British Columbia. His research is on implicit learning, the process through which knowledge about the world about us is picked up largely independently of awareness of both the process and products of that learning. http://academic.brooklyn.cuny.edu/userhome/psych/areber/
\end{abstract}

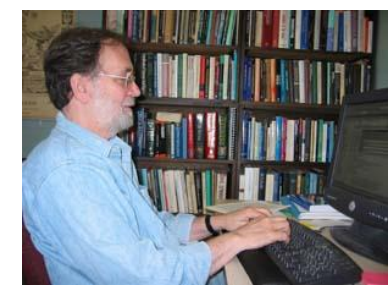

Morsella \& Reyes seem to approve of my primary move, that single-cell species possess a rudimentary form of consciousness. I agree with them, of course - having spent a halfcentury studying the processes underlying implicit learning (see Reber, 1967, 1989, 1993) - that understanding how conscious and unconscious processes play themselves out in the human brain is a key goal in understanding human cognition. But these concerns aren't relevant to the issues raised by the $\mathrm{CBC}$ model.

If, as I am arguing, a primitive form of consciousness or sentience is a property of the simplest living organisms, then there are, a fortiori, mechanisms through which these subjective states are modified over evolutionary time to fit within the growth in complexity and function seen throughout speciation.

Take, for example, the issue of individuality (Godfrey-Smith, 2016; Pradeau, 2016). Here, mechanisms emerged that gave rise to individuals as distinct entities rather than a collection of cells, each of which was/is also a distinct entity. As species became more complex and evolved an ever-wider variety of forms and functions, they constantly underwent these kinds of changes. The CBC simply assumes that they were accompanied by the emergence of more complex forms of sentience.

$\mathrm{Ng}$ is concerned that my "requirement of 'a sensitivity to its surrounds' may make the axiom or statement a tautology if 'sensitivity' requires subjectivity." The direct entailment is correct. It is tautological. While a tautology is generally viewed as a weak rhetorical device, 
I've embraced it. In the $\mathrm{CBC}$, adjectives like subjective, sentient, sensitive, and phenomenal and their nominal and adverbial forms share overlapping linguistic privileges of occurrence.

$\mathrm{Ng}$ notes that conscious species have flexible behaviors. I agree. Single-cell species do have flexible behaviors. They move; they approach some objects; withdraw from others; incorporate still others. Ng's stance is that such behaviors do not require conscious decisions. But, in the CBC framework, to withdraw from something that is sensed as having negative valence is a decision - a pretty simple one but certainly one that is accompanied by a subjective state. The whole point of the model is to emphasize the evolutionary continuity of function. That a behavior is (relatively) hard-wired does not entail that it inhibits phenomenal experience.

And, in passing, I never said it was "... better to go beyond brains to the level of primitive organisms." I said it was a good research strategy that has a high likelihood of success. I am all for studying brains.

Where I suspect that $\mathbf{N g}$ and I may have a fundamental disagreement is over this comment (p. 3):

"... a more immediately important problem is to know with high and increasing degrees of probability which species of animals are capable of affective sentience. For nonsentient species, we do not have to care about their welfare, as they do not have any welfare."

Since the position of the $\mathrm{CBC}$ is that even the simplest of organisms have "affective sentience," it follows that all organisms have "welfare." It behooves us to not cause pain or suffering when it can be avoided or is not balanced by other considerations. In Reber (1997), the first paper on this topic, I wrote:

It began innocently enough. I was watching this small green caterpillar munching on one of my new basil plants. Having become ... an easy-going soul who doesn't feel he has the right to extinguish life, I resisted my initial impulse to flatten [it]....With this sense of the integrity of (relatively benign) life forms guiding me, I spent some time with my herbal interloper, gauging its behavioral assault on my basil.

I still stand by that. The CBC model is also a framework for examining issues in bioethics. I hope to undertake such an exploration in the future.

Safina claims that I have kicked the can down the road. He is right. I have. I am not a molecular biologist and have no solution to the question of how subjectivity is created in single-celled organisms. I merely claim that it is so created.

The point of the target article was to encourage a redirection in thinking and research, to promote a reductionist position where biologists would focus attention on the problem and philosophers of mind could be deflected from framing topics in ways that obfuscate rather than clarify. It was to encourage a broader sense of the scope of mental life. 
I have no concrete solution to my version of the "hard problem," only words of encouragement to others. But I am pleased that Safina appreciates my writing.

Broude seems to have misunderstood my position. I certainly never claimed that evolution of sentience occurs "without gradual accretion and quantitative change with nothing novel added." Of course, novel functions, forms, processes and mechanisms are added. Homo sapiens has semantic memory, Aplysia californica does not. But both species share fundamental biological operations that allow cells to encode representations of events experienced. The consciousness of birds, octopuses, chimpanzees and us are all vastly different from that of the eukaryote, but they share a common foundation.

Nothing in the CBC entails an abandonment of qualitative change or argues that evolution can be captured by models based only on quantitative shifts. Both Woodruff (2016) and Ristau (2016) commented on this issue of saltationist processes and in my earlier reply (Reber, 2016b) I agreed, noting that "pure continuity here is not a requirement."

Similarly, the CBC approach does not, as Broude suggests, neglect the complex interactions between genetic changes and the resulting forms and functions. Her statement that "A gradual change in the genome does not guarantee a gradual change in, say, the brain. Nor does a gradual change in the brain necessarily lead to a gradual change in mind or behavior" is presented as a criticism of the CBC. It isn't. I concur. In fact, these operations are implicitly embodied in the CBC.

Last, Broude seems to invite (if not embrace) the dualism of Chalmers (1995) when she states that what's missing from my analysis is "feeling." I rather thought Nagel cleared this one up years ago. We cannot know what, for example, fish-pain feels like. Only a fish does. But we have several routes to getting a handle on this issue. There are behavioral indicators like withdrawal and future avoidance, physiological measures like tissue damage and repair mechanisms, and evolutionary considerations like those implicated by the CBC model.

My stance is that of a strict mechanist. To identify all the relevant factors is precisely to explain the feeling of pain. A color-blind scientist can come to understand the nature of color vision without ever experiencing the distinction between red and green. I don't know what a $22-\mathrm{kHz}$ tone sounds like to a dog; I don't know what a cheese sandwich tastes like to Broude but I'm content to have a full, scientifically sound description of them and that will have to do.

What I'm trying to avoid is falling into the dualist's trap that somehow there is something more here, some aspect of subjective experience that cannot be "explained" by an exhaustive analysis of physical factors. Down this road lies mysterianism. 


\section{References}

Broude, G. J. (2016). Still wondering how flesh can feel. Animal Sentience, 11(13).

Chalmers, D. (1995). Facing up to the problem of consciousness. Journal of Consciousness Studies, 2, 200-219.

Godfrey-Smith, P. (2016). Individuality, subjectivity and minimal cognition. Biology and Philosophy, 31, 775-796.

Morsella, E. \& Reyes, Z. (2016). The difference between conscious and unconscious brain circuits. Animal Sentience, 11(10).

Ng, Y-K. (2016). Consciousness and evolutionary biology. Animal Sentience, 11(11).

Pradeau, T. (2016). The many faces of biological individuality. Biology and Philosophy, 31, 761-773.

Reber, A. S. (1967). Implicit learning of artificial grammars. Journal of Verbal Learning and Verbal Behavior, 6, 855-863.

Reber, A. S. (1989). Implicit learning and tacit knowledge. Journal of Experimental Psychology: General, 118, 219-235.

Reber, A. S. (1993). Implicit learning and tacit knowledge: An essay on the cognitive unconscious. NY: Oxford University Press.

Reber, A. S. (1997). Caterpillars and consciousness. Philosophical Psychology, 10, 437-450.

Reber, A. S. (2016a). Caterpillars, consciousness and the origins of mind. Animal Sentience, 11(1).

Reber, A. S. (2016b). Resolving the hard problem and calling for a small miracle. Animal Sentience, 11(9).

Ristau, C. A. (2016). Beginnings: Physics, sentience and LUCA. Animal Sentience, 11(4).

Safina, C. (2016). Reber's caterpillar offers no help. Animal Sentience, 11(12).

Woodruff, M. L. (2016). Bacteria and the cellular basis of consciousness. Animal Sentience, 11(2). 